Check for updates

Cite this: RSC Adv., 2019, 9, 32021

Received 14th July 2019

Accepted 27th September 2019

DOI: 10.1039/c9ra05381f

rsc.li/rsc-advances

\section{Superoleophobic micro-nanostructure surface formation of PVDF membranes by tannin and a condensed silane coupling agent $\uparrow$}

\author{
Shuman Feng, $\dot{t}^{\mathrm{a}} \mathrm{Mu} \mathrm{Li}, \mathrm{t}^{\mathrm{b}}$ Songfeng Zhang, ${ }^{\mathrm{b}}$ Yaowen Zhang, ${ }^{\mathrm{b}}$ Bing Wang ${ }^{\mathrm{a}}$ \\ and Lili Wu iD *b
}

\begin{abstract}
A tannin-based hybrid coating was coated on the PVDF membrane surface through a simple one-step codeposition of tannin and KH550. A micro/nano hierarchical structure was formed on the PVDF membrane surface through hydrolysis/condensation of $\mathrm{KH} 550$ and Michael addition reaction between oxidized tannin and an amino group revealed by the field-emission scanning electron microscopy, atomic force microscopy and Fourier transform infrared spectroscopy, which established a harsh surface. Abundant hydrophilic groups and high surface roughness endowed the modified membranes with high hydrophilicity and underwater superoleophobicity. The modified PVDF membranes possess excellent oil/ water separation and antifouling performance due to the underwater superoleophobicity. Moreover, the modified membrane exhibited outstanding stability.
\end{abstract}

The oil/water separation process, especially for separating emulsified oil-in-water emulsions, has become an increasingly important part of water treatment as more and more oily wastewater has been produced from industrial processing and oil spills. ${ }^{1-5}$ Among many conventional methods, polymerdominated filtration technology has been widely applied to water treatment for its simple operation, low cost and easy control of pores. ${ }^{6-10}$ Polyvinylidene fluoride (PVDF) is a promising membrane material owing to its excellent mechanical and chemical properties. However, the intrinsic hydrophobicity makes PVDF easily fouled during treatment of aqueous solutions containing organic matters, decreasing its service life, which has limited its application in the field of oil/water separation. ${ }^{11-14}$ Thus, it is of great importance to improve the hydrophilicity of PVDF porous membranes for highly efficient and eco-friendly separation of oily wastewater.

The concept of bio-adhesion stems from mussel adhesion protein (MAP) with broad adhesion potency. MAP rich in catechol, amino acids and 3,4-dihydroxyphenylalanine (DOPA) allows mussels to adhere to a variety of materials. Dopamine containing amine and catechol groups exhibits a molecular structure similar to that of DOPA, and has become a focus of attention as a novel bioadhesive coating. ${ }^{15-19}$ Low-cost tannin,

${ }^{a}$ People's Hospital of Henan Province, Zhengzhou, Henan, 450003, China

${ }^{b}$ School of Materials Science and Engineering, Wuhan University of Technology, Wuhan 430070, China. E-mail: polym_wl@whut.edu.cn

$\dagger$ Electronic supplementary information (ESI) available. See DOI: 10.1039/c9ra05381f

\$ These authors contributed to the work equally and should be regarded as co-first authors. which has analogous polyphenols units with dopamine, has also been reported to have excellent interfacial properties and could be coated on a variety of substrates including hydro-

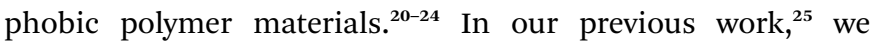
demonstrated that the plant tannin layer can strongly construct on the surface of the PVDF membrane and effectively improve the hydrophilicity and filtration performance of PVDF membrane. In this work, in order to further enhance the underwater superoleophobicity of PVDF membrane for oil-inwater emulsion separation, we constructed a tannin-based hybrid coating on the PVDF membrane surface through a simple one step co-deposition of tannin and (3-aminopropyl) triethoxy-silane (KH550) which is a silane coupling agent containing amino group. On the one hand, hybrid coating can coat on the PVDF membrane surface because of the existence of polyphenols tannin, on the other hand, tannin and KH550 can bond together by means of Michael addition reaction between oxidized tannin and amino of KH550, at the same time, hydrolysis and condensation of KH550 can form crosslinking agents, which can greatly enhance the adhesive ability of coating layer.

The modified membranes were fabricated through a simple one step dip-coating method in plant tannin and KH550 hybrid solution in the context of a weak alkaline solution ( $\mathrm{pH} 7.8)$ and contacting with atmosphere. Fig. 1 shows the co-deposition pathway. The phenolic group of tannin is oxidized to benzoquinone under weakly alkaline conditions and undergoes a Michael addition reaction with the amino group in KH550. ${ }^{26-28}$ The alkoxy group of the silane coupling agent has a hydrogen bond with the phenolic hydroxyl group of the tannin after 


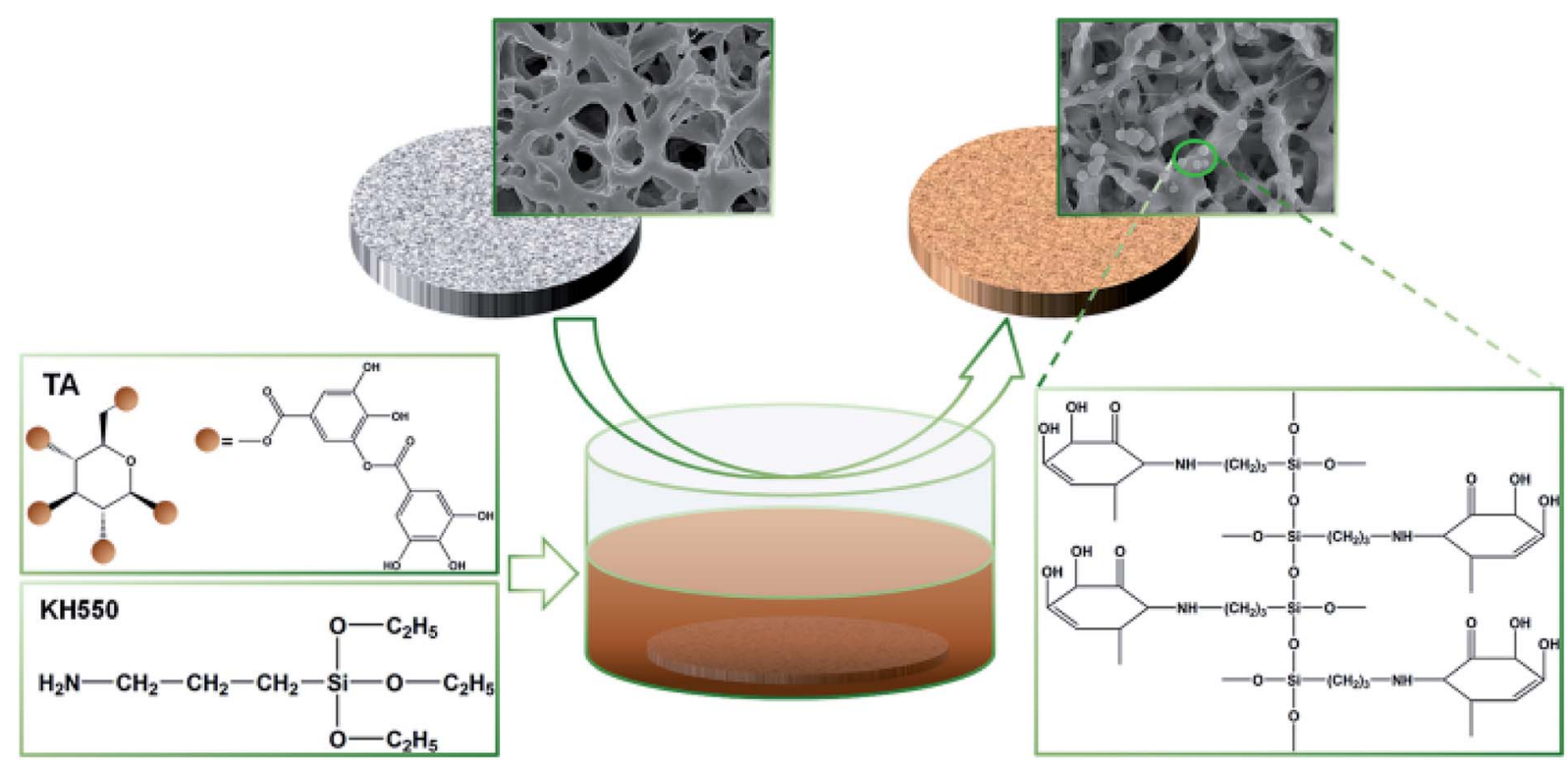

Fig. 1 The co-deposition pathway of tannin and KH550 for membrane modification.

hydrolysis, and will condense with itself to form a siliconcontaining oligomer. Tannin and KH550 form a strong coating on the membrane surface through this complex crosslinking structure. The silicon-containing oligomer produced by KH550 changed the surface morphology and roughness of the membrane surface, and the wettability of the membrane surface was significantly improved.

The surface morphology of the pristine membrane (TK-0) and modified membranes with different adding contents of KH550 were observed via FESEM and AFM, which can be seen in the Fig. 2a and b. As indicated by the FESEM images in Fig. 2a, some spherical particles have formed on the all modified membranes through co-deposition process, but the size and number of particles are greatly different among various membranes. With increasing the content of KH550, the particle size and number sharply increase. Moreover, it can be seen that the top surface of TKN-0.6 is almost completely coated by the particles, which shows a micro/nano hierarchical structure. These phenomena can be rationalized by the formation of hybrid oligomer. The more the content of KH550 in the codeposition process, the more and bigger hybrid oligomer will be formed through hydrolysis and condensation reaction of KH550. AFM images are shown in Fig. 2b, the roughness obviously increased with extending the content of KH550. This result corresponds with the FESEM and indicates the formation of micro/nano structure. Interestingly, the roughness of TK0 are higher than TKN-0.15, it can be explained that the main part of the coating layer on the TKN-0.15 are tannin due to the less adding content of KH550, which can form a homogeneous coating with a few particles. In contrast to polydopamine, our modified membranes show a slight change in color (Fig. S1 $\dagger$ ), which indicates that this novel process has more widely application.
The deposition ratio (DR) can directly reflect the amount of coating layer which deposited on the membranes. As increasing of the content of KH550, the DR of the modified membranes are increasing linearly, which demonstrates that more hybrid oligomer was formed and anchored on the membrane surface (Fig. S2 $\dagger$ ). The surface chemical elements and groups are critical for wettability of materials. The XPS spectrum of the membranes were shown in Fig. $2 c$ and Table S1, $\dagger$ and the elemental compositions of different modified membranes were determined. The presence of oxygen, nitrogen, and silicon elements can be confirmed in the XPS spectrum, wherein the oxygen element is derived from tannin and KH550, and the nitrogen and silicon elements are derived only from PVP. Therefore, the $\mathrm{Si} / \mathrm{O}, \mathrm{Si} / \mathrm{C}$ and $\mathrm{O} / \mathrm{C}$ ratio can illustrate the content of tannin and KH550 applied to the surface of the membrane to a certain extent. The atomic ratio about $\mathrm{Si} / \mathrm{O}, \mathrm{Si} / \mathrm{C}$ and $\mathrm{O} / \mathrm{C}$ are all raising with the increase of KH550, this shows that more silicon-containing oligomers are fixed on the membrane surface. These indicate that tannin and KH550 have codeposited on membrane surface successfully. This result is also confirmed by ATR-FTIR measurement (Fig. S3†). Four notably absorption peaks at $1608 \mathrm{~cm}^{-1}, 1499 \mathrm{~cm}^{-1}, 1323 \mathrm{~cm}^{-1}$, and $1098 \mathrm{~cm}^{-1}$ were detected, which assigned to skeletal vibration of aromatic rings, $\mathrm{N}-\mathrm{H}$ bending vibrations, $\mathrm{C}-\mathrm{N}$ stretching vibration and $\mathrm{Si}-\mathrm{O}-\mathrm{Si}$ stretching vibration, respectively. These imply that a lot of hydrophilic groups have coated on the hydrophobic PVDF membrane surface, which can significantly improve its hydrophilicity.

As an interfacial issue, membrane surface energy and surface roughness can simultaneously affect the wettability. ${ }^{29-32}$ According to Wenzel's model, roughness can increase the actual contact area between droplet and substrate, thus improving the hydrophilicity and total surface energy of hydrophilic substrate. ${ }^{33,34}$ In this work, the hybrid coating layer contains 
a)

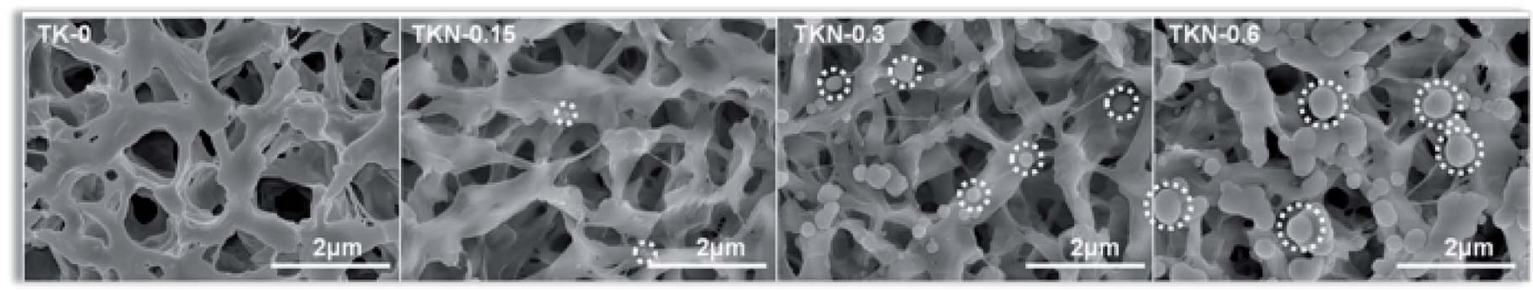

b)

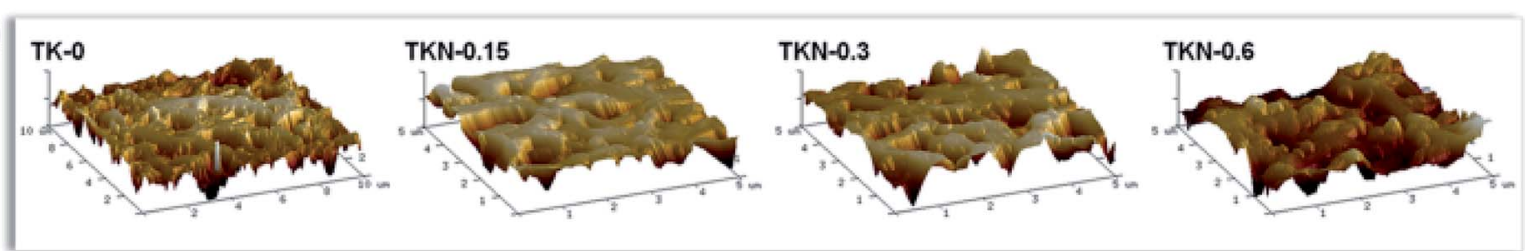

c)

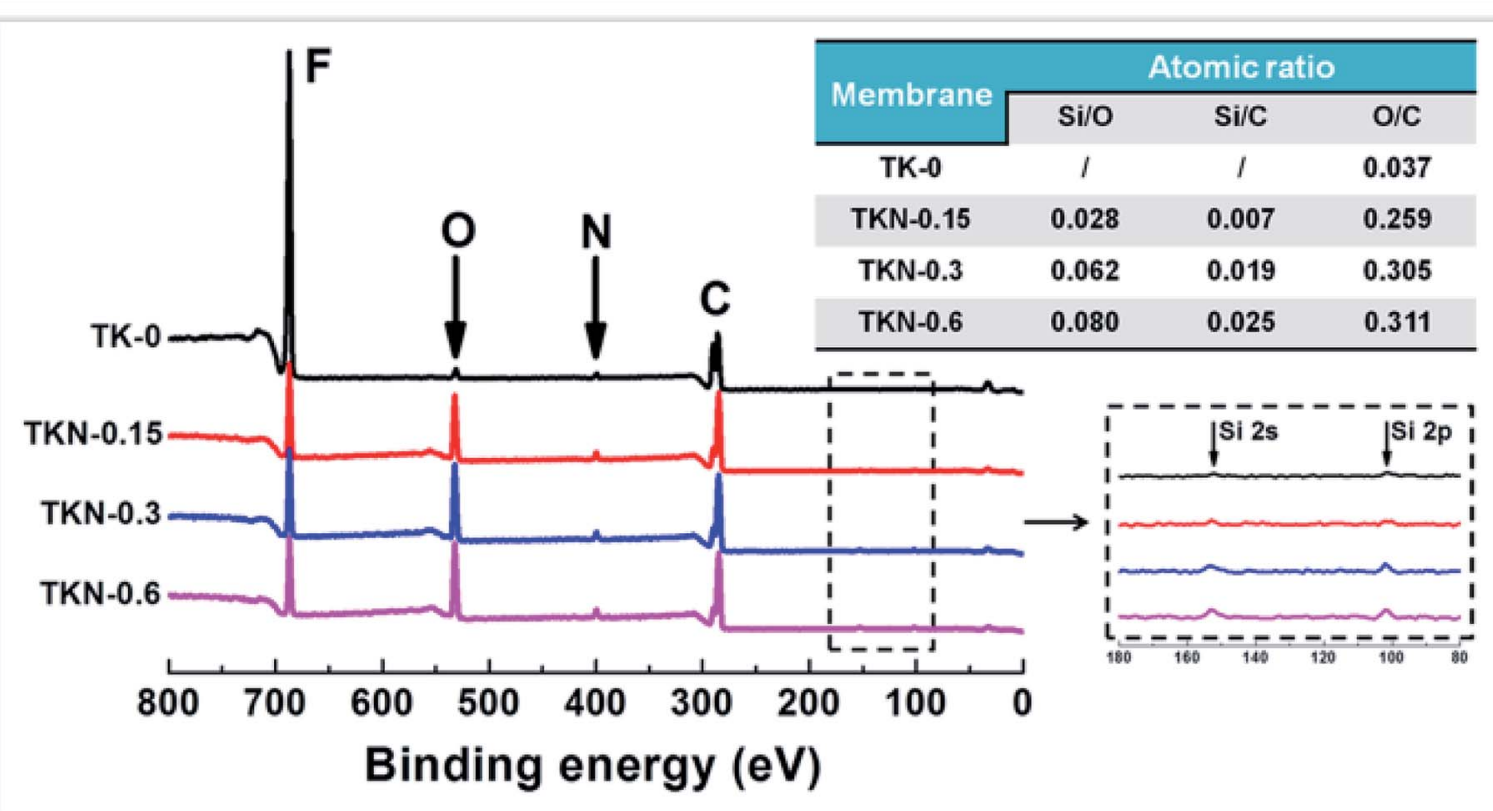

Fig. 2 Characterizations of morphology and chemical composition of the different PVDF membranes. (a) FESEM images of the membrane top surface. (b) AFM images of the membrane top surface. (c) XPS spectra and atomic ratio of the membrane surface.

abundant hydrophilic groups, thus, the hydrophilicity of modified PVDF membranes have improved greatly. As shown in Fig. 3a, the water contact angle (WCA) of modified membranes sharply decreased comparing with TK- 0 , and the minimum WCA value was occurred to TKN-0.3 rather than TKN-0.6, which indicates that this modified process exists a threshold WCA with the increase of KH550. The water droplet permeation of modified membrane can be observed in Fig. 3b, the WCA rapidly decrease to $0^{\circ}$ within $5 \mathrm{~s}$, which exhibit much high hydrophilicity. Fig. 3b shows the dynamic underwater oiladhesion property of TKN-0.6. An extremely low oil-adhesion performance was detected, it can be explained that a water barrier has formed on the modified PVDF membrane surface under water due to the high hydrophilicity, which can greatly reject the oil droplets and effectively decrease fouling. The underwater oil contact angle (OCA) directly revealed the excellent oleophobicity of our modified membranes as shown in Fig. $3 \mathrm{c}$ and $\mathrm{d}$. The underwater chloroform contact angle of different membranes are raising with the increase of KH550.
The value of TK-0 is $127^{\circ}$, but the modified membranes are all higher than $150^{\circ}$, the value of TKN-0.6 is $163^{\circ}$ which show a outstanding oleophobicity. Therefore, underwater different oils (dichloromethane, toluene, petroleum ether and diesel) contact angle of TKN-0.6 were measured to further characterize the oil repelling performance. It can be seen that the OCA of four oils are $161^{\circ}, 162^{\circ}, 163^{\circ}$ and $156^{\circ}$ respectively, indicating a underwater superoleophobic property which is critical to oil/ water separation. This underwater superoleophobicity is caused by the cooperation of high hydrophilicity and roughness of tannin and KH550 hybrid coating.

The pure water flux, emulsion filtration flux and flux recovery ratio (FRR) were measured by a vacuum driven filtration system (Fig. S4 $\dagger$ ) to evaluate filtration performance, as shown in Fig. 4. The pristine membrane and modified membranes were all wetted before measurement to avoid the compaction effect. The pure water flux was shown in Fig. 4a, the flux value of pristine membrane is $14133 \mathrm{~L} \mathrm{~m}^{-2} \mathrm{~h}^{-1}$, however, the modified membranes are $18982 \mathrm{~L} \mathrm{~m}^{-2} \mathrm{~h}^{-1}, 19863 \mathrm{~L} \mathrm{~m}^{-2} \mathrm{~h}^{-1}$ and 
a)

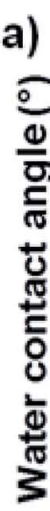

a)

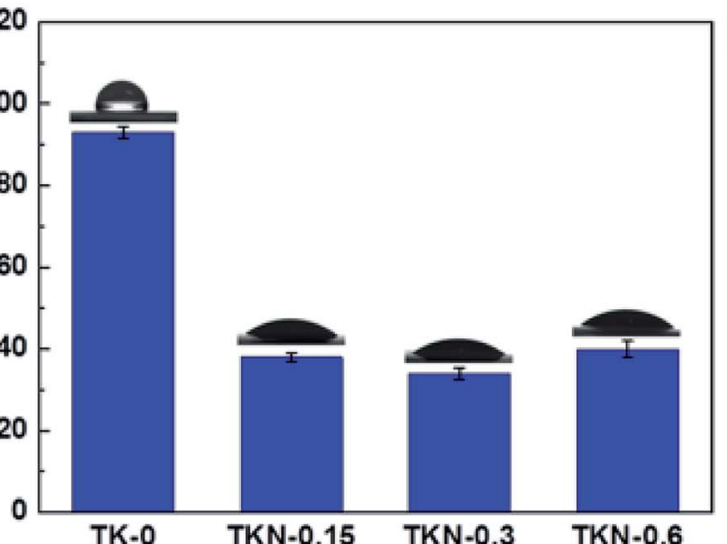

TK-0

TKN-0.15

TKN -0.3

TKN-0.6 b)

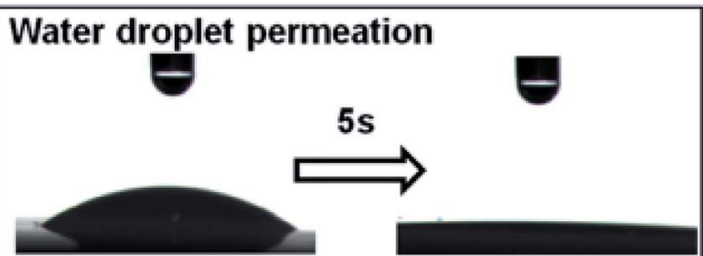

Dynamic underwater oil-adhesion

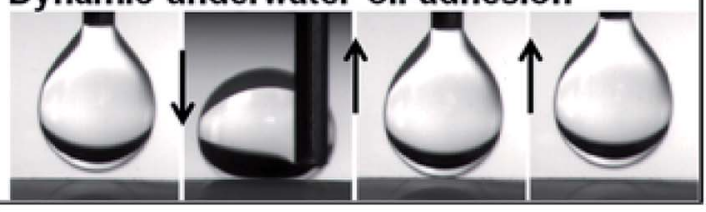

c)

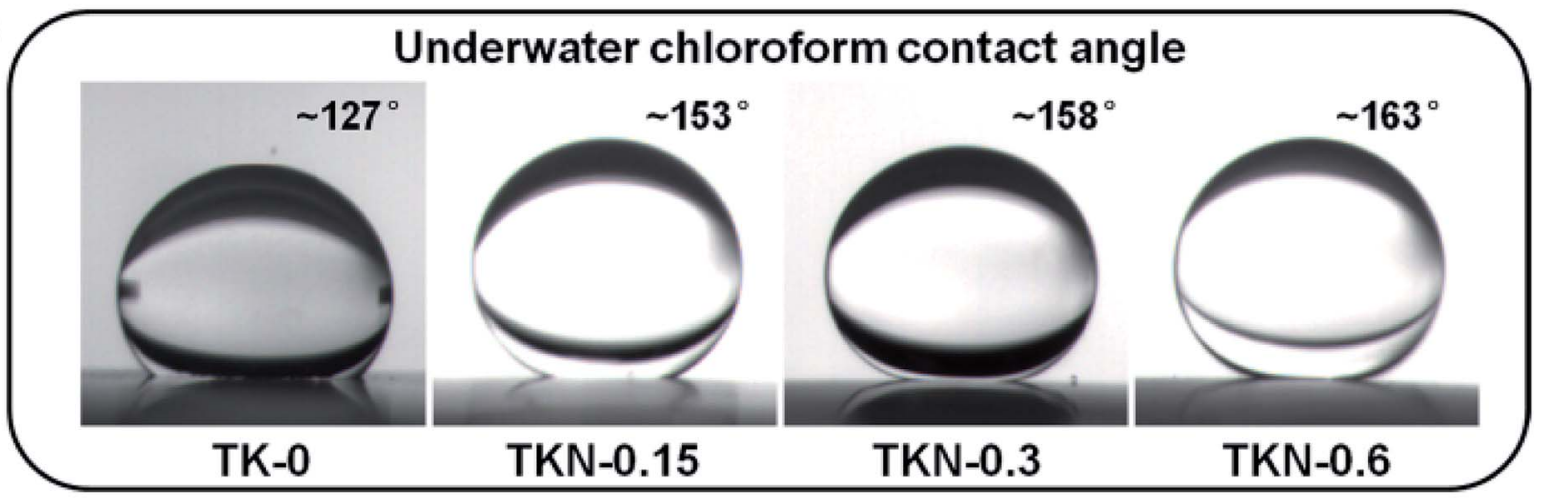

d)

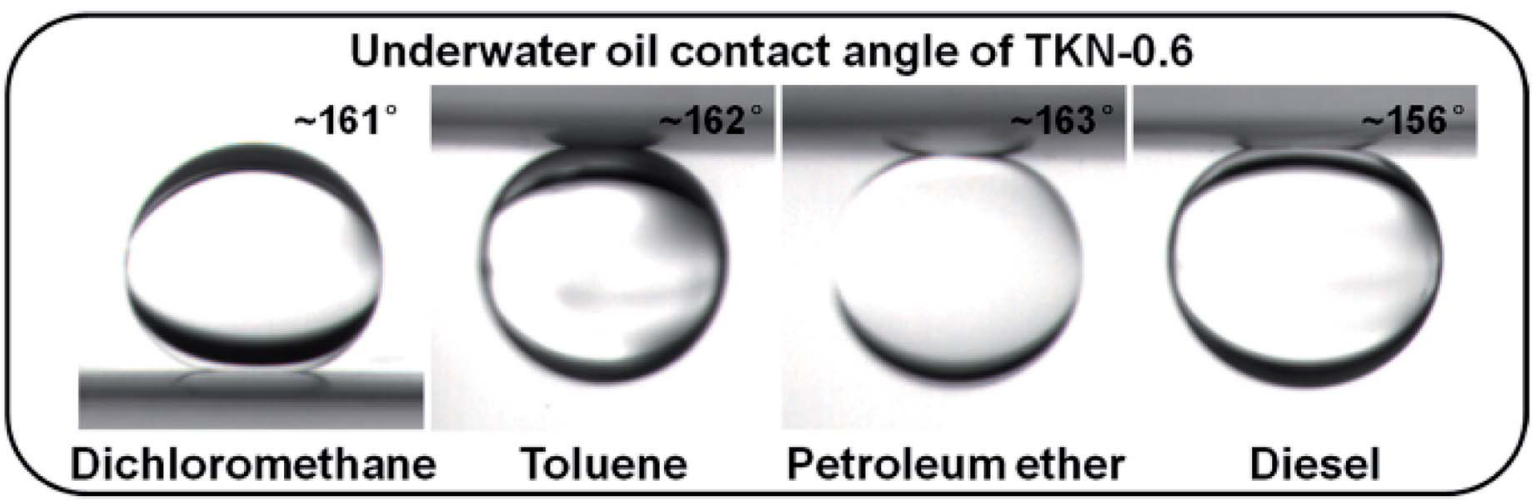

Fig. 3 Characterizations of hydrophilicity and oleophobicity of the different PVDF membranes. (a) Water contact angle of membrane surface. (b) Water droplet permeation and dynamic underwater oil-adhesion measurements. (c) Underwater chloroform contact angle of various membranes. (d) Different oils underwater contact angle of TKN-0.6.

$18480 \mathrm{~L} \mathrm{~m}^{-2} \mathrm{~h}^{-1}$ respectively, which are much higher than pristine membrane. This result is triggered by the excellent hydrophilicity of coating layer on modified membranes. Meanwhile, the slightly different flux values among the modified membranes can be detected, which result in the blocking of micro/nano particles. The emulsion filtration performance is shown in Fig. 4b, the prepared emulsion had an average particle diameter of $487 \mathrm{~nm}$ as measured by a Malvern particle size analyzer. The flux value of pristine membrane is $782 \mathrm{~L} \mathrm{~m}^{-2} \mathrm{~h}^{-1}$, however, all the modified membranes exhibit high emulsion filtration flux, as the flux of $2512 \mathrm{~L} \mathrm{~m}^{-2} \mathrm{~h}^{-1}, 4178 \mathrm{~L} \mathrm{~m}^{-2} \mathrm{~h}^{-1}$ and $4632 \mathrm{~L} \mathrm{~m}^{-2} \mathrm{~h}^{-1}$ for TKN-0.15, TKN-0.3 and TKN-0.6 respectively were obtained. This indicates the great emulsion separation efficiency of modified membranes. After filtration, the toluenein-water emulsion is transformed into transparent exhibited by the inset images. The underwater superoleophobic property of modified membranes is the main reason for this outstanding filtration performance. The antifouling property was characterized by flux recovery ratio (FRR) shown in Fig. 4c. It can be seen that the FRR value of modified membranes are all higher than the pristine membrane (82\%) and all more than $98 \%$, even reaches $100 \%$ for $\mathrm{TKN}-0.3$ and $\mathrm{TKN}-0.6$. This excellent antifouling property should give the credit to the superoleophobic property which is aroused by the high hydrophilicity and roughness of tannin and KH550 hybrid coating. To measure the stability of modified membranes, a water rinsing experiment 

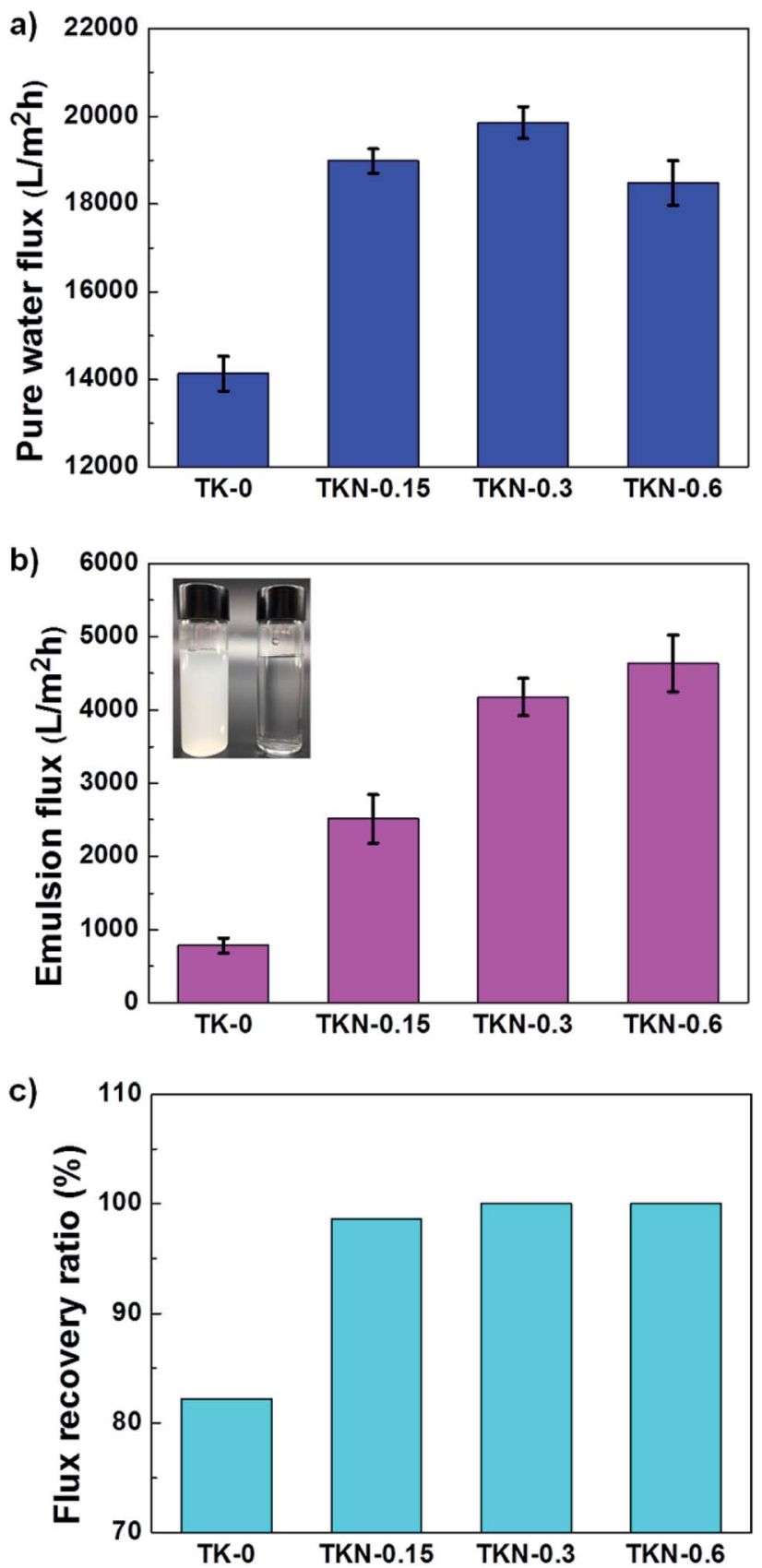

Fig. 4 Filtration performance of the different membranes. (a) Pure water flux of the wetted PVDF membranes. (b) Flux of toluene-inwater emulsion, inset images is the emulsion before (left) and after (right) filtration. (c) Flux recovery ratio after the emulsion separation.

was taken and underwater chloroform contact angle was measured to evaluate the stability of underwater superoleophobic property of modified membrane (Fig. 5a). It is found that the underwater chloroform contact angle of TKN-0.3 stabilized at $157-160^{\circ}$ during seven days rinsing, which disclosed the outstanding stability of hybrid coating coated PVDF membrane. As shown in Fig. 5b, the emulsion flux declines gradually with the increase of time due to the fouling of the membrane. The emulsion flux was almost completely recovered a)

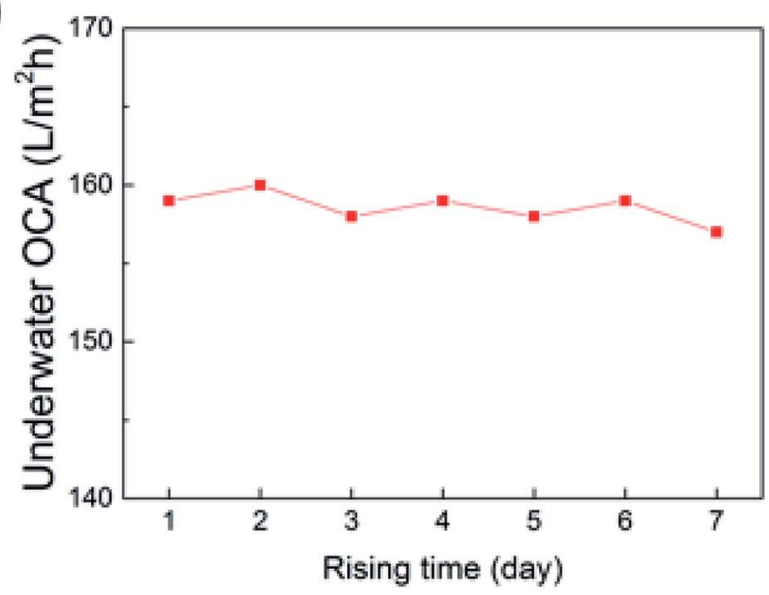

b)

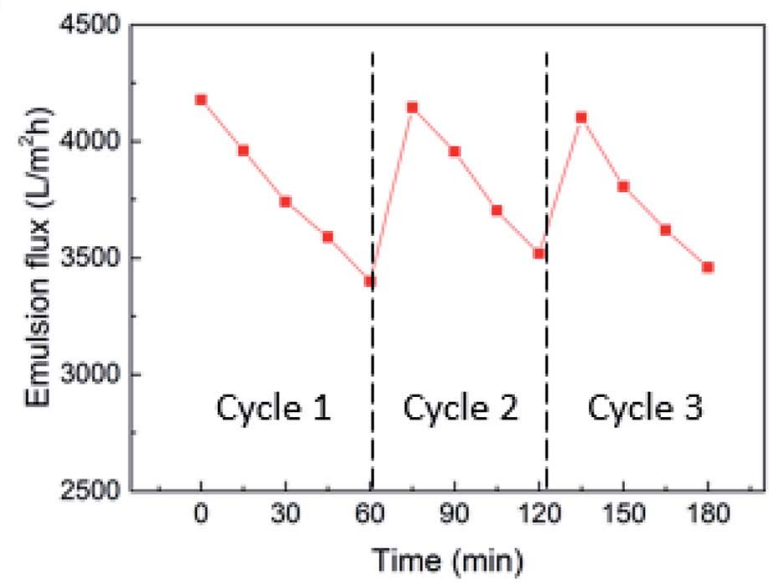

Fig. 5 (a) The underwater chloroform contact angle of TKN-0.3 membrane during the pure water rinsing test for 7 days. (b) Emulsion flux and flux recovery over three cycles.

by washing with pure water after 1 hour of emulsion filtration, indicating the stability of the TKN-0.3 membrane.

In summary, a hydrophilic and underwater superoleophobic PVDF membrane was fabricated through a simple one step codeposition method, the low cost tannin and commercial KH550 hybrid coating layer was coated on PVDF membrane surface successfully. A micro/nano hierarchical structure, which can be adjusted by the adding content of KH550, was observed on the modified membrane surface. It can increase the roughness of membrane surface and obtain an excellent hydrophilic and underwater superoleophobic property. The underwater superoleophobicity endows the membrane with a superior antifouling property (underwater oil contact angle reaches $160^{\circ}$, FRR reaches 100\%) and high oil/water separation efficiency (the emulsion flux reaches $4600 \mathrm{~L} \mathrm{~m}^{-2} \mathrm{~h}^{-1}$ ). The great performance indicates that this strategy is promising for practical applications in the field of treating oily wastewater.

\section{Experimental section}

The tannin solution was extracted from the mixture solution of tara powder and deionized water $(1 / 10, w / w)$, which has been 
stirred for $4 \mathrm{~h}$ and left to stand overnight at room temperature. The modified membranes were fabricated through a simple dipcoating method. Firstly, commercial PVDF membranes were pre-wetted by isopropyl alcohol for $0.5 \mathrm{~h}$ and then placed in deionized water for at least $1 \mathrm{~h}$ to prepare for modification. Secondly, the extracted tannin aqueous solution $(100 \mathrm{~mL})$ was adjusted $\mathrm{pH}$ to weak alkaline with Tris-buffer $(50 \mathrm{mM}, \mathrm{pH} \approx$ 7.8), then certain amounts of KH550 (0.15 g, $0.3 \mathrm{~g}$ and $0.6 \mathrm{~g}$ ) dissolved in $20 \mathrm{~mL}$ ethanol was immediately mixed with abovementioned alkaline tannin solution. Thirdly, the per-wetted PVDF membranes were immersed in the mixture solution for $12 \mathrm{~h}$ contacting with atmosphere at room temperature. Finally, the modified membranes were rinsed deeply by deionized water and placed in deionized water or dried in air for further research. The various modified membranes were named TKN0.15 , TKN-0.3 and TKN-0.6 according to the adding content of KH550. For comparison, the pristine membrane was immersed in deionized water for $12 \mathrm{~h}$ which was named TK-0. Detailed procedures for a series of characterizations are provided in the ESI. $\dagger$

\section{Conflicts of interest}

There are no conflicts to declare.

\section{Acknowledgements}

This work was financially supported by Program of Young Scholar sponsored by China Scholarship Council (201306955022) and Students Innovation and Entrepreneurship Training Program sponsored by Wuhan University of Technology (20161049701006).

\section{References}

1 S. Jamaly, A. Giwa and S. W. Hasan, J. Environ. Sci., 2015, 37, 15-30.

2 Z. Xue, Y. Cao, N. Liu, L. Feng and L. Jiang, J. Mater. Chem. A, 2014, 2, 2445-2460.

3 Q. Ma, H. Cheng, A. G. Fane, R. Wang and H. Zhang, Small, 2016, 12, 2186-2202.

4 Z. Chu, Y. Feng and S. Seeger, Angew. Chem., 2015, 54, 23282338.

5 Y. Zhu, D. Wang, L. Jiang and J. Jin, NPG Asia Mater., 2014, 6, e101.

6 J. Yin and B. Deng, J. Membr. Sci., 2015, 479, 256-275.

7 D. Rana and T. Matsuura, Chem. Rev., 2010, 110, 2448-2471.

8 M. M. Pendergast and E. M. V. Hoek, Energy Environ. Sci., 2011, 4, 1946.
9 D. J. Miller, D. R. Dreyer, C. W. Bielawski, D. R. Paul and B. D. Freeman, Angew. Chem., 2017, 56, 4662-4711.

10 V. Kochkodan and N. Hilal, Desalination, 2015, 356, 187-207.

11 Z. Cui, E. Drioli and Y. M. Lee, Prog. Polym. Sci., 2014, 39, 164-198.

12 G.-d. Kang and Y.-m. Cao, J. Membr. Sci., 2014, 463, 145-165.

13 F. Liu, N. A. Hashim, Y. Liu, M. R. M. Abed and K. Li, J. Membr. Sci., 2011, 375, 1-27.

14 J. Ji, F. Liu, N. A. Hashim, M. R. M. Abed and K. Li, React. Funct. Polym., 2015, 86, 134-153.

15 Z. Wang, X. Jiang, X. Cheng, C. H. Lau and L. Shao, ACS Appl. Mater. Interfaces, 2015, 7, 9534-9545.

16 Y. Xiang, F. Liu and L. Xue, J. Membr. Sci., 2015, 476, 321329.

17 L. Shao, Z. X. Wang, Y. L. Zhang, Z. X. Jiang and Y. Y. Liu, J. Membr. Sci., 2014, 461, 10-21.

18 Z.-X. Wang, C.-H. Lau, N.-Q. Zhang, Y.-P. Bai and L. Shao, J. Mater. Chem. A, 2015, 3, 2650-2657.

19 Y. L. Ji, M. B. M. Y. Ang, H. C. Hung, S. H. Huang, Q. F. An, K. R. Lee and J. Y. Lai, J. Membr. Sci., 2018, 557, 58-66.

20 T. S. Sileika, D. G. Barrett, R. Zhang, K. H. Lau and P. B. Messersmith, Angew. Chem., 2013, 52, 10766-10770.

21 D. G. Barrett, T. S. Sileika and P. B. Messersmith, Chem. Commun., 2014, 50, 7265-7268.

22 L. Pan, H. Wang, C. Wu, C. Liao and L. Li, ACS Appl. Mater. Interfaces, 2015, 7, 16003-16010.

23 X. Zhang, P.-F. Ren, H.-C. Yang, L.-S. Wan and Z.-K. Xu, Appl. Surf. Sci., 2016, 360, 291-297.

24 X. Zhang, Y. Lv, H. C. Yang, Y. Du and Z. K. Xu, ACS Appl. Mater. Interfaces, 2016, 8, 32512-32519.

25 S. Zhang, L. Wu, F. Deng, D. Zhao, C. Zhang and C. Zhang, RSC Adv., 2016, 6, 71287-71294.

26 H. C. Yang, K. J. Liao, H. Huang, Q. Y. Wu, L. S. Wan and Z. K. Xu, J. Mater. Chem. A, 2014, 2, 10225-10230.

27 X. Zhang, P. F. Ren, H. C. Yang, L. S. Wan and Z. K. Xu, Appl. Surf. Sci., 2016, 360, 291-297.

28 S. Ryu, Y. Lee, J. W. Hwang, S. Hong, C. Kim, T. G. Park, H. Lee and S. H. Hong, Adv. Mater., 2011, 23, 1971-1975.

29 B. Su, Y. Tian and L. Jiang, J. Am. Chem. Soc., 2016, 138, 17271748.

30 R. Du, X. Gao, Q. Feng, Q. Zhao, P. Li, S. Deng, L. Shi and J. Zhang, Adv. Mater., 2016, 28, 936-942.

31 Y. Dong, J. Li, L. Shi, X. Wang, Z. Guo and W. Liu, Chem. Commun., 2014, 50, 5586.

32 M. Liu, Y. Zheng, J. Zhai and L. Jiang, Acc. Chem. Res., 2010, 43, 368.

33 R. N. Wenzel, Ind. Eng. Chem., 1936, 28, 988-994.

34 J. Jiang, L. Zhu, L. Zhu, B. Zhu and Y. Xu, Langmuir, 2011, 27, 14180-14187. 